DOI: $\underline{10.20472 / T E .2016 .4 .3 .003 ~}$

\title{
THE TRIANGLE OF SOCIAL COMPETENCE DEVELOPMENT
}

\author{
UTE TAT, NATASCHA ZEITEL-BANK, LEENA SAURWEIN
}

\begin{abstract}
:
The current paper focuses on social competencies as a necessity for being successful in professional life on the basis of a triangle analysis. It is demonstrated how intra- and interpersonal competencies could be already developed during the academic career through different learning settings based upon scientific foundations, each emphasising an individual, team and global level respectively. It has been shown that these levels are intricately interwoven. Since this complex developmental process depends on several influencing factors, for success, an integrated learning setting is required to support future professionals to applicate effective interpersonal skills in diverse teams in a globalised world.
\end{abstract}

\section{Keywords:}

Social Competencies, Self-Leadership, Learning in Teams, Intercultural Communication

JEL Classification: 123

\section{Authors:}

UTE TAT, Management Center Innsbruck, Austria, Email: ute.tat@mci.edu NATASCHA ZEITEL-BANK, Management Center Innsbruck, Austria, Email: natascha.zeitel-bank@mci.edu LEENA SAURWEIN, Management Center Innsbruck, Austria, Email: leena.saurwein@mci.edu

\section{Citation:}

UTE TAT, NATASCHA ZEITEL-BANK, LEENA SAURWEIN (2016). The Triangle of Social Competence Development. International Journal of Teaching and Education, Vol. IV(3), pp. 16-32.,

10.20472/TE.2016.4.3.003 


\section{Introduction}

Social competencies are the requirements for being successful in life. The main challenge for education lies in the design of effective settings for the development of social competencies. Thus, more and more universities are keen to include this field in their curriculum on a European and global level. In our paper, we outline key features of social competencies and show possible ways of developing particularly intra- and interpersonal competencies. Therefore, we discuss three different learning settings (i.e. course designs) regarding self-leadership development, learning in teams and intercultural communication.

Social competencies for this purpose in our understanding comprise social skills like communication, conflict management and empathy, as well as personal competencies such as self-leadership, and they might occur on three different levels within and across organizations respectively:

- On an individual level (Me) the competence of self-leadership primarily implies self-awareness, the ability to create positive thought pattern as well as empathy.

- On a team level (We) interpersonal competencies are linked to learning in teams, communication in teams and the understanding of team dynamics in general.

- Across the organization and on a global level (Us) interpersonal competencies regarding intercultural aspects, diversity and cross cultural communication move into the centre of attention.

In the Me-We-Us Model (see fig.1), we illustrate the interdependencies of social competencies on these levels and take into consideration both, the verbal and nonverbal perspective on communication. 


\section{Figure 1: The Me-We-Us Triangle of Social Competencies}

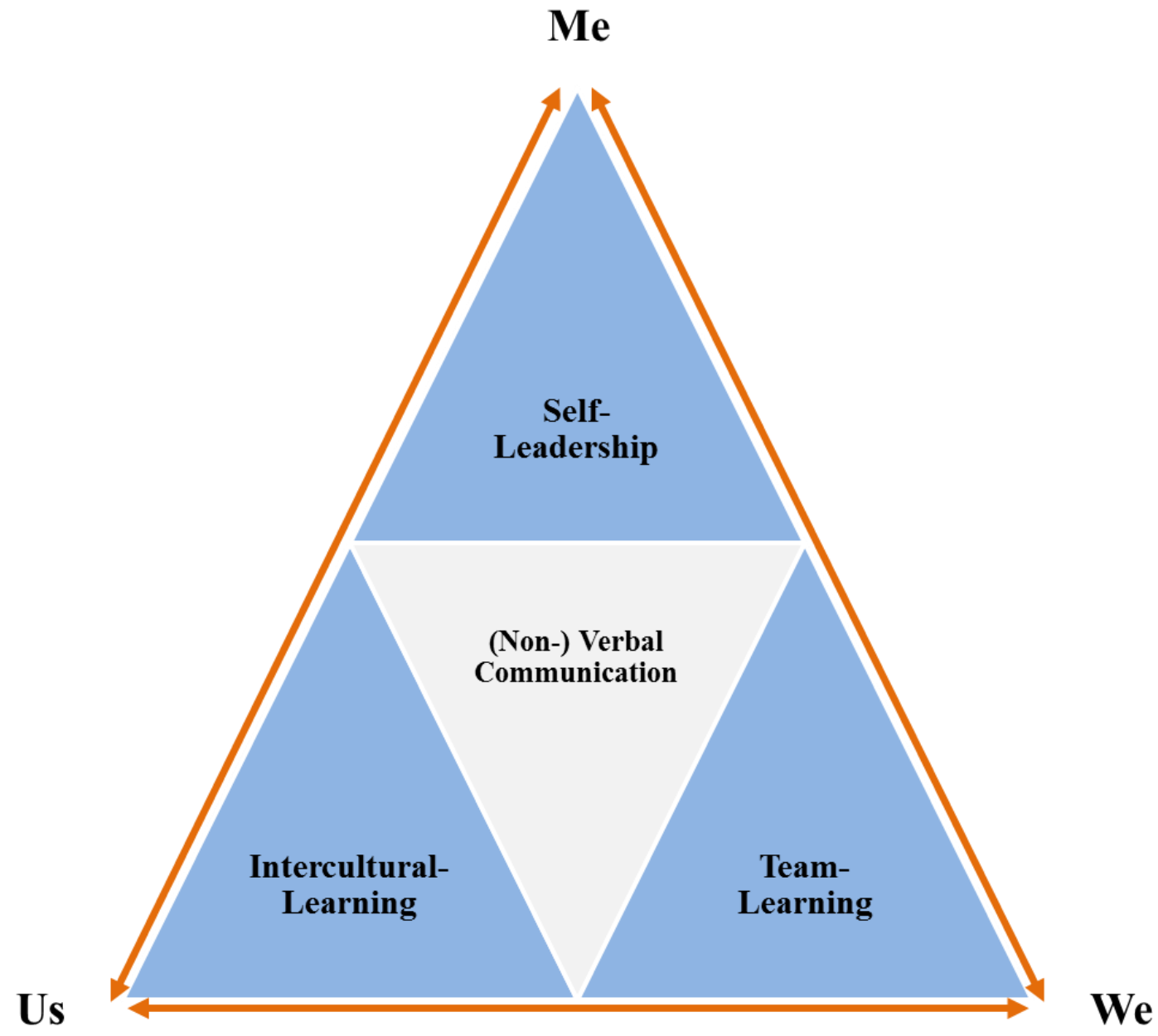

Source: Own illustration

Communication can be seen as the centrepiece in the development of social competencies that occurs on a verbal and nonverbal level. Since the body plays a crucial role in nonverbal communication and in learning processes in general, we apply the idea of embodiment for the design of an effective learning setting. The analysis, reflection and development of learners' social competencies on the mentioned anchor points and levels support the future professionals to applicate effective interpersonal skills in diverse teams and to become good communicators in their respective field of business in a globalized world.

From an educational point of view the development of competencies can be seen as a staged process, aimed at enabling learners to apply knowledge in concrete situation. This requires that learners undergo a real experience. In other words, the process of competency development is according to Kolb (1984) understood as a lifelong learning process of doing and reflecting. 
Each of the following discussed course designs is based upon scientific foundations, with emphasize on a hands-on approach.

\section{Self-leadership}

On the individual level (Me) the emphasis is set on self-leadership competencies, especially on the competencies of self-awareness, empathy, and creating constructive thought pattern.

Self-leadership can be described as a self-imposed influence process that in general aims to support individuals to deal effectively with this complex world. It emphasizes an individual's capacity to manage and control one's own behavior by using specific sets of behavioral and cognitive strategies, for example, observation and imagination. The roots of the concept of self-leadership primarily lie in psychology (see Neck \& Manz, 2013, Neck \& Houghton, 2006, p.270). Self-leadership comprises the following strategies:

Behaviour-focused strategies, aimed at identifying and changing undesirable behaviour, mainly focus on the self-awareness for one's own actions, including self-observation, self-reward and self-cueing. Natural reward strategies are related to intrinsic motivation. Constructive thought pattern stresses the positive influence of habitual thinking pattern, and include identifying and replacing dysfunctional beliefs, mental imagery, and positive self-talk (Neck \& Houghton, 2006, pp.271-272).

We assume that the competencies that are needed for applying self-leadership strategies can hardly be developed through formal learning methods on a purely abstract cognitive level, but rather through experience, to be concrete through bodily experience.

Since there is evidence from a variety of studies and disciplines that show how the body informs and shapes cognition, the body can be seen as a key factor in shaping the mind (Gallagher, 2013, pp.8-9). The idea that cognition is embodied challenges education and "points to the need to move from abstract teaching and learning to grounded teaching and learning." (Ionescu \& Vasc, 2014, p.277) Thus, there seems to be a need for embodied learning approaches and conceptual designs for application respectively. Therefore, we suggest moving the body more into the center of attention in learning settings.

To support students in developing self-leadership competencies through bodily experience and awareness along with intellectual reflection, an embodied learning approach to strengthen several self-leadership competencies has been developed and integrated in a master`s program (Tat \& Zeitel-Bank, 2013, p. 187). 
From an educational point of view, an embodied learning approach merges the experiential learning cycle (see Kolb, 1984; Law, 2010) with the idea of embodiment: At the stage of experience learners are engaged in a bodily experience and then observe its effects on them. By processing this bodily experience, learners are encouraged to understand what they did, thought and felt during the bodily experience. Then the learners try to generalize their experience, which means to understand the general principle behind the relationship between the action and its effects and finally, the learners are elated to apply the learned to a new situation.

The main challenge seems to be how the respective competencies such as selfawareness, empathy, and creating constructive though pattern, could be developed. However, first of all there is a need to clarify the respective competencies:

Self-awareness and the meaningful awareness of others are not entirely separate forms of cognition (Tsakiris et al., 2007, p.658-659). With regard to self-leadership, awareness has a twofold meaning: being aware of oneself and being aware of others. Awareness from an experiential learning point of view might be experienced through perceiving one's own interests or restriction and through perceiving interests or restriction of others. Whereas the former belongs to self-awareness, the latter seems to belong to empathy.

Empathy here is meant in the sense of understanding others, and that, in turn, presupposes awareness of others. To increase the competence of empathy (i.e. to be able to understand others better), it might be supportive to develop the competence of awareness in general (i.e. awareness of others and self-awareness). In that sense, selfawareness can be understood as a prerequisite for empathy and, thus, might serve as a basis respectively. Being aware of oneself, experienced through the perception of one's own interests or restriction (i.e. mindsets), might support being aware of others.

In an embodied learning approach, raising awareness might be possible through experiencing and reflecting on both, a bodily and cognitive level. Since the competencies of self-awareness and empathy (i.e. the levels of $\mathrm{Me}$ and $\mathrm{We}$ ) are intricately interwoven, the development of these competencies might be possible together in one learning approach - an integrated embodied approach of learning.

The competence of creating constructive thought pattern encompasses positive self-talk and mental imagery (Neck \& Houghton, 2006, p.272). Mental imagery supports creating and symbolically experiencing behavioral outcomes prior to actual performance (Manz \& Neck, 1991; Neck \& Manz1992, 1996; as cited in Houghton \& Neck, 2002, p. 674). By analyzing self-talk patterns, pessimistic self-talk can be replaced with more optimistic selfdialogues (Seligman, 1991, as cited in Neck \& Houghton, 2006, p.272). The development of the competence of creating constructive thought pattern might be facilitated through 
experience and intellectual reflection within the cycle of experiential learning. With regard to an embodied learning approach, a possible way to experience and to reflect positive self-talk and mental imagery might be through practicing on both, a bodily and cognitive level.

On a practical basis the respective competencies are experienced and, thus, developed in the following way:

- To experience self-awareness, the learners practice mindful, bodily movements, forced to concentrate on themselves, and to be centred in the moment they are presently in. A special breathing technique supports them in concentrating on a strong centred mind. Since active listening is one important interpersonal skill, self-awareness in this sense means focusing on the inner perspective. Learners practice to listen inside their body to better understand their own needs and emotions as well as accepting their own restrictions (Tat \& ZeitelBank, 2013, p. 187-188).

- In terms of empathy it is suggested that an enhanced understanding of own needs, emotions and restrictions might lead to a better understanding of the needs, emotions and restrictions of others. Furthermore, the learning setting enables learners to increase their sensitivity in terms of empathy through observing nonverbal communication. Due to the structure of the course the learners practice both, nonverbal communication and verbal communication.

Through practicing mindful, bodily movements learners increase their sensitivity of nonverbal communication in terms of body posture and body language. The verbal communication part at the end of each unit (i.e. a get-together) facilitates the heterogeneous team members in their team developmental process. It enables them to become more familiar with each other and to increase their team cohesiveness (Tat \& Zeitel-Bank, 2013, p.188). This points out again the interdependency of social competencies on the levels of $\mathrm{Me}$, We, and Us respectively, by emphasizing the holistic view of (non)verbal communication.

- Creating constructive thought pattern is practiced by being engaged in positive thoughts during the bodily movements. Learners are forced to mentally practice a task and imagine successfully how to perform it beforehand. Positive self-talk in the form of internal communication assists decision-making processes and creates a 'can-do' belief. Supporting positive thinking becomes a habit and might enable learners to transfer this ability to work and its accomplishment (Tat \& Zeitel-Bank, 2013, p.188).

At the end of the embodied learning process learners are supposed to have acquired hands-on experience in self-leadership. In particular, they should be able to apply selected self-leadership competencies in their daily work life. This might contribute to the 
learners' self-efficacy, motivation, and final performance (Tat \& Zeitel-Bank, 2013, p.187188).

By and large, on completion of this two-semester long embodied learning process, it has been shown that all students - from their own point of view - could strengthen their social competencies, regardless if they liked or disliked this unusual learning setting. To be concrete, the students' benefit was amongst others to increase their competencies of awareness, constructive thought pattern and empathy. Moreover, they seem to be capable of applying selected self-leadership competencies in their daily lives. The overall course contributed to their mental and bodily well-being in general.

Thus, the students have acquired hands-on experience in self-leadership that might contribute to their self-efficacy, motivation, and final performance (Tat \& Zeitel-Bank, 2013, p.187-188).

Success or failure in the discussed learning setting as well as the experienced broad range of acceptance and refusal might be due to the differences in personal characteristics of the participants, their experiences, and their preferred styles of learning. Furthermore, environmental and situational factors influence the effectiveness of the respective learning setting and give room for interdisciplinary research on this challenging topic.

\section{Learning in teams}

On the team level (We) interpersonal competencies are linked to learning, working and communicating in teams and understanding team dynamics not only on a theoretical, but also on a practical training level.

Teams are a group of people "who exist to perform organisationally relevant tasks, share one or more common goals, interact socially, exhibit task interdependencies, maintain and manage boundaries, and are embedded in an organisational context that sets boundaries, constrains the team, and influences exchanges with other units in the broader entity" (Kozlowksi \& Bell 2003, p.334). Wagemann, Gardner, and Mortensen (2012) define a team as a "bounded and stable set of individuals interdependent for a common purpose" (p.305). On the team level interpersonal competencies are linked to learning and communicating in teams and understanding team dynamics e.g. conflicts in general (see McShane \& Von Glinow, 2010; Griffith \& Dunham, 2015; Knights \& Willmott, 2007).

Teamwork consists of specific factors, which are central for the overall success. This reflects the We level of the triangle of the social competences model. Those factors are (MIT, n.d.): 
- "shared understanding of the team's mission

- commitment to the team's goals

- clearly defined roles and responsibilities

- agreed upon ground rules

- an established decision-making model

- effective group process including commitment to open communication, mutual accountability and appropriate self-evaluation."

In the We team learning setting students come very close to the real life experiences. They have to work on real projects delivered by an external partner and are supported and challenged in this process with theoretical input from lectures in empirical research, project management and scientific work. At the same time they have to communicate efficiently and effectively within the team and with the external partner in a given time, budget and scope. At the end, the final results are summarized in a final scientific paper followed by presentations for the public (Zeitel-Bank \& Tat 2012).

In this learning setting the teams have to work on three levels, which make the learning setting complex and challenging:

- Among the team members: In team-based companies, teams are composed of people from different professions or jobs to combine all the knowledge and skills for one common goal (Katzenbach \& Smith, 1993). In this learning setting, students are all in the 'same boat' with a similar background and without, any hierarchies at least, at the start. The advantage: Homogenous teams tend to be more effective on tasks required and have a high degree of cooperation and coordination (MacDahen \& Von Glinow, p.245). Students have to determine their respective role in the team and capacities of each team member for fulfilling the attributed task for the sake of the overall project result. This goes along with the application of classical project management tools like the creation of an organigram and the establishment of a project break down structure plan, which contains the respective work packages for each team member.

The process of task distribution goes along with an important discussion process and a process of self-evaluation of the respective role and working type. This self and team reflection process is an important part of the We definition, also in defining common rules, shared expectations and norms: "The more closely the person's social identity is connected to the group, the more the individual is motivated to avoid negative sanctions from the group" (McShane \& Von Glinow, p.249.) These negative sanctions could be being late, not to fulfill the designed task in time and the due quality.

Furthermore, team members are involved in the five C's processes of Cooperating, Coordinating, Communicating, Comforting, Conflict resolving: "These characteristics of effective team members are associated with conscientiousness 
and extroversion personality traits as well as with emotional intelligence (McShane \& Von Glinow, p.244). Here, again, the Me level has an important impact on the We level.

- Between the team and the team leader: Working on a one semester project it is important not only just to nominate a team leader to act in daily routine activities like controlling and (social) coordination, but especially to assume responsibility in solving difficult and critical conflicts in situations on the interpersonal level in teams. The designated project leader has to act in the new role in guiding the student colleagues and bringing them back on the right track for the sake of the overall project. It may happen that students refuse to nominate a team leader highlighting that they are working all together without hierarchal thinking. However, in the long run, experiences have shown that the position of a team leader has to be fulfilled after a while.

- On the external level between the group and the lecturers and between the group and the external partner: On the external level students have to distinguish the internal and the external environment. Whereas, in companies teams or the respective team leader report to the same responsible supervisor, the environment in this learning setting is even more complex. Students have to report to several lecturers who guide them as experts in their respective expert fields (empirical research, scientific work, project management) and at the same time to the external partner who has assigned them the related project. This means to oppress possible conflicts in the team and to be professional in external comportment (inner / outer border).

Students have to respect the changed setting and to learn to behave in a due way - bearing in mind that they are representing the institution as well as market their own person as a future potential applicant after having finished studies. A clear project assignment, a sound preparation for the meetings and a clear documentation (minutes) are essential on this external level relationship. Here students will train the We aspect on a multilevel, changing and challenging surrounding.

In all those situations verbal and nonverbal communication plays a central role and is the bridging element in and between all levels for team work and for overcoming conflict situation in teams, for instance, due to lack of commitment, productivity losses, interpersonal conflict and poor leadership (Griffith \& Dunham, 2015, p.5). It is evident, that the often quite heterogeneous composition of the team from the personality point of view (Me) provokes the traversing of different interpersonal stages of group dynamics. The most known model describes the four phases by Tuckman (1965): forming, storming, norming, performing. 
This model was complemented by Susan Wheelan (1999) in the first stage (forming) with the terms dependency and inclusion, in the second stage (storming) with counter dependency and fight, in the third stage (performing) with trust and structure, in the fourth stage with work and productivity. So the second and third phases are determined by instability (Gersick 1988).

When groups perform highly uncertain tasks, they need to integrate large amounts of information, form multiple perspectives, and collaborate closely (Thompson, 2004, p.238). Conflict is "disagreement, discord, and friction that occur when the actions or beliefs of one or more members of the group are unacceptable to and resisted by one or more of the other group members" (Forsyth, 2010, p.380). It is often in the storming phase when serious conflicts emerge. Discontent may occur because norms are ignored which could provoke a negative reaction on a nonverbal (grimaces when being late) and verbal level (sarcastic comments) from the other group members. This may even deteriorate the overall atmosphere. "Once we are willing to view conflict as a common occurrence, it loses some of its gravity and can be approached from a pragmatic, less emotional perspective" (Griffith \& Dunham, p.54).

During this phase the lecturer is often the right person for advice and problem solving if the group and especially the still inexperienced project leader is not able to find a solution in a conflicted situation. A clear communication plan and group rules help to overcome possible barriers. All in all, a clear communication is the centerpiece of success in delivering the final assignment which includes empirical research and the project handbook in the due time combined in a proper way. Computer-Mediated Communication (CMC) might help the group as a whole to facilitate the output and general outcome of the project, e.g. presentation tools, drop box, blogs, Skype, open source platforms. Even if the respective tools, plans and programmes facilitate the workflow and prevent or solve communication barriers and conflicts, students learn in those networked surroundings that just following the visible and evident line is not enough. They have to understand that communication takes place not only in the classical verbal way.

This understanding of nonverbal or paraverbal communication is even more important and goes along with the principle of active listening. As Mehrabian's experiments showed the general meaning or impact of an inconsistent message: Thus, the impact of facial expression is greatest, then the impact of the tone of voice (or vocal expression), and finally that of words - the famous $7 \% / 38 \% / 55 \%$ formula (Mehrabian 1972, p.43). Nonverbal cues are, for instance, facial expressions, level of eye contact, body movements, paraverbal are above all vocal qualities. "An accurate perception of nonverbal communication helps the listener understand the intent of the speaker and is strongly related to social intelligence and interpersonal sensitivity" (Goleman, 2006 as cited in Griffith \& Dunham, p.96). It is not only important to decode, but also to understand the message in the right way for avoiding any conflicted situations or 
misunderstanding in the respective communication process. By working together in close proximity over an extended period, students have to develop a rhythm, rapport, common identity and trust.

Thus, at the end of the semester, students got a basic practical and theoretical knowledge of team work and team dynamic and are trained not only in the Me aspect but above all in the We feeling. In this learning setting, students had to work on the following explicit and implicit questions:

- Why is a clear communication important and which tools / plans could help to facilitate the work flow and prevent or solve communication barriers / conflicts?

- At which level does communication take place (verbal, nonverbal or paraverbal with what effect and are there any gender differences)?

- What are the strategies for getting the message across and engaging in active listening?

\section{Intercultural communication}

Across the organization and on a global level interpersonal competencies regarding intercultural aspects, diversity and cross cultural communication move into the centre of attention. Here at the global level (Us) comes into fore, when we refer to the Me-We-Us Model.

Self-awareness, and the formation of small cultures are the main aspects in developing intercultural competences and efficient intercultural communication. Self-awareness as already dealt with at the Me level concentrates here at the Us level on understanding the cultural resources that impact oneself. It is defining what is culture for oneself and what is one's cultural imprinting.

According to Holliday (2013) social and political structures, global position and politics, personal trajectories, cultural products and statements about culture make up our cultural resources.

- Particular social and political structures are the way we are educated, the governmental form, media, economy - all that influence our daily lives.

- The global position and politics denotes how we position ourselves and our society with regard to the rest of the world, for example, how the East and the West see each other. A very important aspect as it is the Self and the Other - constructions of who we are in relationship to others. This can at times, reflect in extreme ethnocentric behaviour and attitude of 'otherism' towards the other members.

- Personal trajectories the individuals' family, ancestors, peers as well as the individuals travel through life where they collect their own cultural realties around them and culture is constantly renegotiated. 
- Particular cultural products like cultural artefacts (e.g. the arts, literature) as well as the cultural practices, which we perform daily (eat, greet, show respect etc.) play an influential role.

- Statements about culture, how we present ourselves and what we choose to call our culture develop over the years.

All these cultural resources give individuals their cultural imprinting and make them aware of their own culture. Self-awareness of one's own culture helps individuals to negotiate the cultural realities of everyday life. It can be said, that these cultural resources are universal in nature as all individuals across the globe experience them; they participate in and negotiate their position within the cultural landscape they belong forming the basis upon which we are able to read culture (Holliday 2013, p.3).

Over and above, self-awareness (Me) in view of culture, understanding one's mindset towards interculturalism is of underlying importance in the global context. It is vital to know the way one construes cultural differences in order to develop the intercultural competences to be able to navigate efficiently across cultures. The Intercultural Developmental Inventory (IDI) tool - is one such tool, which determines the level of sensitivity of individuals. The IDI is based on the Developmental Model of Intercultural Sensitivity (DMIS), which was developed with a grounded theory approach (see Glaser \& Strauss, 1967; Strauss \& Corbin, 1990) where theoretical concepts are used to explain patterns that emerge from systematic observations. This tool is designed to help individuals understand their mindsets on a developmental continuum, which may range between a monocultural and intercultural mindset.

In respect to, the Me-We-Us Model, the We involves team building and working in teams which are fairly homogeneous in nature. Likewise, the Us deals with formation of groups and teams, however, at the global level these groups and teams would tend to involve people from diverse backgrounds and may be very heterogeneous in nature. The focus here in Us lies predominantly in the formation of small cultures, which constantly take place in our daily lives as individuals automatically take part in or begin to build small cultures.

In the field of intercultural communication, small culture formation are small social groupings or activities wherever there is cohesive behaviour, for instance, families and workgroups where people form rules for how to behave and bind them together. The notion of small cultures does not mean that they are essentially small in size. Small cultures are the basic cultural entities from which all other cultural realities grow. Individuals are always and all the time in the process of constructing and dealing with cultural realities (Holliday, 1999, p.240). 
In addition, in the field of intercultural communication research, small cultures are distinct from large cultures. The large cultures tend to highlight the essential differences between ethnic, national and international entities. They refer mainly to the essences of ethnic, national and international entities, for example, 'individualistic' and 'collectivistic' nature of certain ethnic, national entities, the different concept of time, space etc. perceived by different national entities as a norm.

Thus, they tend to explain behaviour as prescriptive, for instance, Germans are said to be punctual and task-oriented, whereas Indians are said to be unpunctual and more relationoriented due to the different concept of time and individualistic vs. collectivistic traits that are seemingly apparent in these countries respectively. Large cultures tend to denote that behaviour is national in these terms. The focus of a large culture approach is what makes cultures, which everyone acknowledges as existing and essentially different to each other, whereas the small culture approach is more concerned with social processes as they emerge (Holliday 1999, p.241).

Small cultures, in cultural research, are denoted as heuristic, which means, it is involved in the process of interpreting group behaviour. It is reckoned that cultural resources or as the large culture approach states 'cultural dimensions' such as individualistic vs collectivistic etc., different time, space, concepts etc. can and are found in all types of social groupings but may or may not possess significant ethnic, national or international qualities. Small culture is, thus, "the sum total of all the processes, happenings or activities in which a given set or several, sets of people habitually engage. It can, hence, be said that small culture is more to do with activities taking place within the group than with the nature of the group itself" (Holliday 1999, p.248).

Small culture formation is, therefore, a dynamic ongoing group process, which operates in changing circumstances to enable group members to make sense of and operate meaningfully within those circumstances. In order to operate meaningfully and successfully at the global level, it is important to understand the interactive process of communication i.e. both verbal and nonverbal communication. Since this occurs in a global context, one's self-awareness (Me) in view of culture (Us) as well as one's level of cultural sensitivity towards others must be known to oneself, to navigate successfully with team members coming from different backgrounds.

In the course design to understand intercultural communication and to build further intercultural competences, the learning setting is made up of a 3-phase course. From the educational point of view, this 3-phase course embeds the experiential learning cycle (see Kolb 1984). The theoretical input as well as the IDI taken by learners facilitates the learners - the understanding of one's culture, cultural imprinting, one's level of cultural sensitivity, small cultural formations and large cultural approach. Next, the concrete experiences made by the learners are expressed in writing so that they understand and 
realise what they went through and finally this reflection is discussed with the facilitator so that the learner understands the general principles involved and can apply the learned to forthcoming situations.

The learning setting primarily aims to:

- Prepare students for their semester abroad

- Help students understand their own culture

- Help students understand probable traits in the host culture

- Support students in learning how to shift perspectives

- Lessen/prevent culture shock

- Encourage students to avoid stereotypes

In the Phase 1 students take the IDI prior to the beginning of the face-to-face session. The focus in that session lies on the small culture approach where it is attempted to make students understand the dynamic nature of culture and emergent behaviour in small cultures. Nonetheless, students' attention is also drawn to the large culture approach and its dimensions as mentioned above. However, the small culture approach is strongly propagated. The theoretical input is further complemented by exercises, discussions and with tools such as films. Students are also urged to come for a personal feedback on their IDI prior to their international sojourn. As stated earlier the IDI underpins students' selfawareness (Me) in view of culture (Us) as it helps students understand where they stand in view of their intercultural mindset as well as the IDI helps facilitators understand where the group and the individual student stand.

The Phase 2 of the lesson takes place when students are abroad. During their international sojourn, where students make their concrete experiences. They have to write reflections on two out of three incidents. The questions are customized and based on their respective IDI results. The questions are posted on the Intranet platform and they encourage students to reflect upon their experiences made in forming small culture (We \& Us) during their international social or academic environment and, on the other hand, to increase their self-awareness $(\mathrm{Me})$ in view of culture and to facilitate movement on the developmental continuum. With the small culture approach it is anticipated that students will focus on searching for and observing the interaction between several cultures within the given target scenario. In this interpretive and reflective process the students will discover and learn more about their own small culture, which is aligned "within the specificities of a wider mélange" (Sarangi, 1995, as cited in Holliday, 1999, p.252).

The Phase 3 of the course is a debriefing session, which takes place when the students are back from their sojourn. This is either face-to-face or via Skype. Here, the reflection work of the students, their realisations and the learned, their general view of their semester abroad as well as their re-entry into their home environment is discussed. 
Students have enjoyed their experiences abroad despite perhaps some problems in communication verbal and nonverbal across different cultures. This has primarily to do with the anxiety they sometimes face in the initial stages of small culture formations. In most cases, the learning setting has stirred some positive psychological disruption inducing efficient work and communication in the field of academia. Students have also, to a great extent, realised that the learning of culture does not necessarily have to do with ethnic, national and international differences.

The students' intercultural development can be inferred from the IDI, which serves as a starting point, from the reflections submitted to the facilitator as well as through the debriefing session at the end of their international stay with the facilitators. This triangulation mix of both quantitative and qualitative data has supported the facilitator in strongly incorporating the raising of self-awareness (Me) in view of culture (Us) and the small culture approach as appropriate to enhance students' intercultural competences in a world, which is becoming increasingly multicultural.

\section{Conclusion}

In higher education one of the main goals and huge challenge likewise, is to develop student's social competencies to enable them to effectively solve the diverse problems they face nowadays. The respective curricula in a study program need to be aligned to support students in developing effective intra- and interpersonal skills in diverse teams and to become good communicators, especially in their field of business in a globalised world.

It has been shown that intra- and interpersonal level are intricately interwoven and the development of social competencies is a complex process that needs time and effort to be successful. The Me-We-Us Model - The Triangle of Social Competencies - illustrates these interdependencies and takes into consideration both, the verbal and nonverbal level of communication. In the presented learning settings success and extend of sustainability depend on several influencing factors such as individual characteristics, quality of both, the learning design and the lecturer as well as the learning environment.

The discussed examples implemented at the three different levels, namely, individual, team and global, pursue the overall goal of developing and strengthening students' social competencies to facilitate them to face the future challenges in the 'real world'. 


\section{References}

Forsyth, D.R. (2010). Group Dynamics (5th edition). Belmont, CA: Wadsworth/Cengage.

Gallagher, S. (2013). How the body shapes the mind. Oxford, UK: University Press.

Gersick, C. J. G. (1988). Time and transition in work teams: Toward a new model of group development. The Academy of Management Journal, 31(1), 9-41.

Glaser, B. Strauss, J. (1967) Discovery of Grounded Theory: Strategies for qualitative research, Aldine Transaction, New Brunswick:NJ.

Griffith, Brain A. \& Dunham, E. B. (2015): Working in teams, moving from high potential to high performance. London: Sage.

Holliday, A. (2011). Intercultural Communication and Ideology. Thousand Oaks, CA: Sage.

Holliday, A. (2013). Understanding Intercultural Communication. Abingdon, Oxon: Routledge.

Houghton, J.D., \& Neck, C.P. (2002). The revised self-leadership questionnaire. Testing a hierarchical factor structure for self-leadership. Journal of Managerial Psychology, 17(8), 672-691.

Ionescu, T., \& Vasc, D. (2014). Embodied cognition: challenges for psychology and education. Procedia Social and Behavioral Science, 128, 275-280.

Katzenbach, J.R. \& Smith, D.K. (1993). The Wisdom of Teams: Creating the High-performance Organization. Boston: Harvard Business School.

Knights, D. \& Willmott, H. (2007): Introducing organisational behaviour and management, Cengage Learning EMEA: Hamphsire.

Kolb, D. A. (1984). Experiential learning. Experience as the source of learning and development. Englewood Cliffs, NJ: Prentice Hall.

Kozlowski, S.W.J. \& Bell, B. S. (2003). Work groups and teams in organizations. In: W. Borman, D. Ilgen, \& R. Klimoski (Eds.), Comprehensive handbook of psychology, Vol. 12: Industrial and organizational psychology (pp. 333-375). New York, NY: Wiley.

Law, B. (2010). Teaching and Learning for a Sustainable Future: Experiential Learning. Retrieved from http://www.unesco.org/education/tlsf/mods/theme_d/mod20.html

McShane, S. L. \& Von Glinow, M. (2010). Organizational Behaviour, emerging knowledge and practice for the real world, 5th edition, New York: McGraw-Hill / Irwin.

Mehrabian, A. (1972). Nonverbal communication. Aldine-Atherton, Illinois: Chicago

MIT (Massachusetts Institute of Technology) (n.d.): Human Resources: Learning and Development. Retrieved from http://hrweb.mit.edu/learning-development/learning-topics/teams/articles/basics

Neck, C. P. \& Houghton, J.D. (2006). Two decades of self-leadership theory and research. Past developments, present trends and future possibilities. In Journal of Managerial Psychology, 21(4), 270-295.

Neck, C.P. \& Manz, C. (2013). Mastering Self-Leadership. Empowering Yourself for Personal Excellence. (6th ed.), Upper Saddle River: Pearson Education.

Sarangi, S. (1995). Culture. In J. Vershueren, J.Oestman \& J.Blomaert (Eds), Handbook of Pragmatics, Amsterdam/Philadelphia: John Benjamins. 
Strauss, A. \& Corbin,J. (1990) Basics of Qualitatitive Research. Techniques and procedures for developing grounded theory. 2nd edition. Sage Publications, Thousand Oaks: CA.

Tat, U. \& Zeitel-Bank, N. (2013). Self-leadership Development. The Link Between Body, Mind, and Reflection. EconPapers. 183-189. Retrieved from http://www.toknowpress.net/ISBN/978-961-691402-4/papers/ML13-244.pdf

Thompson, L., (2004). Making the team: A guide for managers, 2nd edition. Upper Saddle River, NJ. Prentice Hall.

Tuckman, Bruce W. (1965): Developmental sequence in small groups, Psychological Bulletin, 63, 384-399.

Tsakiris, M., Schutz-Bosbach, S. \& Gallagher, S. (2007). On agency and body-ownership: Phenomenological and neurocognitive reflections. Consciousness and Cognition. 16, 645-660.

Wageman, R., Gardner, H., Mortensen, M. (2012). Teams have changed: Catching up to the future, Industrial and Organizational Psychology, 5(1), 48-52.

Wheelan, S. (1999). Creating Effective Teams: A Guide for Members and Leaders. Newbury Park, CA: Sage.

Zeitel-Bank, N. \& Tat, U. (2012). 'Networked Learning' at the Management Center Innsbruck, Austria, EconPapers. 479-487. Retrieved from http://www.issbs.si/press/ISBN/978-961-6813-105/papers/ML12_104.pdf 